\title{
AFRICAN AMERICANS, PAYDAY LENDERS, AND THE FORECLOSURE CRISIS IN MISSISSIPPI
}

Kristen E. Broady, Fort Valley State University, Fort Valley, GA

Aisha G. Meeks, Alabama State University, Montgomery, AL

dx.doi.org/10.18374/JABE-14-1.1

\begin{abstract}
This study analyzes the determinants of county level mortgage foreclosure start rates in the state of Mississippi in order to determine if higher concentrations of underrepresented minority residents and payday lending establishments increase county foreclosure start rates. The results of an ordered logit regression suggest that counties with higher percentages of underrepresented minority residents are likely to have higher foreclosure start rates. However, marriage rates and educational attainment also play a significant role. The results also indicate that a higher exposure to payday lending establishments does not have a significant effect on foreclosure start rates.
\end{abstract}

Keywords: mortgage, minority, payday 